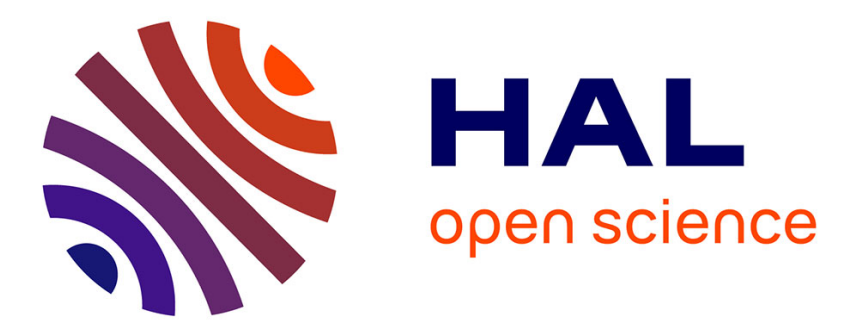

\title{
Young age as a risk factor for complicated course and visual outcome in intermediate uveitis in children.
}

\author{
Viera Kalinina Ayuso, Hermine Adriana Theodore ten Cate, Patricia van Der
} Does, Aniki Rothova, Joke Helena de Boer

\section{- To cite this version:}

Viera Kalinina Ayuso, Hermine Adriana Theodore ten Cate, Patricia van Der Does, Aniki Rothova, Joke Helena de Boer. Young age as a risk factor for complicated course and visual outcome in intermediate uveitis in children.. British Journal of Ophthalmology, 2010, 95 (5), pp.646. 10.1136/bjo.2010.184267 . hal-00588357

\section{HAL Id: hal-00588357 https://hal.science/hal-00588357}

Submitted on 23 Apr 2011

HAL is a multi-disciplinary open access archive for the deposit and dissemination of scientific research documents, whether they are published or not. The documents may come from teaching and research institutions in France or abroad, or from public or private research centers.
L'archive ouverte pluridisciplinaire HAL, est destinée au dépôt et à la diffusion de documents scientifiques de niveau recherche, publiés ou non, émanant des établissements d'enseignement et de recherche français ou étrangers, des laboratoires publics ou privés. 
Young age as a risk factor for complicated course and visual outcome in intermediate uveitis in children.

V. Kalinina Ayuso ${ }^{1}$, H.A.T. ten Cate ${ }^{2}$, P. van den Does ${ }^{1}$, A. Rothova ${ }^{1}$, J.H. de Boer ${ }^{1}$

${ }^{1}$ Department of Ophthalmology, University Medical Center Utrecht, Utrecht, The Netherlands

${ }^{2}$ Faculty of Medicine, Utrecht University, Utrecht, The Netherlands

Corresponding Author:

V. Kalinina Ayuso, MD

Department of Ophthalmology

Postbus 85500

3508 CX Utrecht

Tel: +31-88-755-9640

Fax: +31-88-755-5417

Email:v.kalininaayuso@umcutrecht.nl 
Objective: To identify prognostic factors in intermediate uveitis (IU) in children.

Methods: Retrospective case series of 35 patients with onset of IU $\leq 16$ years and a minimum follow-up of 1 year. Demographic and numerous clinical data were documented. Visual outcomes and development of complications were analyzed in relation to age of onset and ocular signs at presentation.

Results: Forty-six percent of patients had onset $\leq 7$ years and in $54 \%>7$ years. The younger onset group had shorter event-free survival for secondary glaucoma $(p=0.04)$ and vitreous hemorrhage $(p=0.01)$. Mean age of onset in children with cataract (5.9 versus 8.7 years), glaucoma (5.0 versus 8.4 ) and vitreous hemorrhage (5.6 versus 8.5 ) was lower then in children without these complications (all $p=0.03$ ). Frequencies of other complications did not differ between both groups. The younger onset group had worse BCVA's at presentation ( 0.3 versus 0.6 ), at 1 year ( 0.4 versus 0.9 ) and at 3 years followup $(0.6$ versus 0.9 ; all $p \leq 0.04)$ and they needed longer treatment $(p=0.01)$. Children with young onset of IU reached remission less frequently $(p=0.05)$. Development of cystoid macular edema (CME) was independently associated with papillitis (adjusted $H R=3.4$; $\mathrm{p}=0.02$ ) and snowbanking (adjusted $\mathrm{HR}=3.3 ; \mathrm{p}=0.03$ ) at presentation. Other complications at onset were not predictive for future complications.

Conclusions: Children with young onset of IU carry higher risk of complications and worse visual outcome. We would recommend considering more intensive monitoring and earlier threshold for systemic treatment in those children with risk factors as early onset, papillitis and/or snowbanking at initial presentation. 


\section{Introduction}

Intermediate uveitis (IU) occurs in up to $42 \%$ of the pediatric uveitis population and is the second most common form of uveitis in childhood. ${ }^{1}$ Idiopatic IU is characterized by a chronic inflammatory process primarily involving the vitreous, posterior ciliary body and peripheral retina. ${ }^{2}$ Pars planitis (PP) is a form of idiopathic IU characterized by snowballs and snowbanking at the pars plana and peripheral retina in the absence of systemic diseases. ${ }^{2}$

IU in adults can occasionally be associated with systemic disorders or infections; however, in most children the etiology of IU remains unknown. The understanding of the pathogenesis of $\mathrm{IU}$ is still limited; involvement of auto-immune processes and/or a genetic predisposition ${ }^{4-8}$ have been suggested and several familial cases have been reported. $^{9-13}$

The course of IU in children can be worsened by many sight threatening complications. ${ }^{3 ; 14-19}$ Nevertheless in many children and young adults IU can reach remission with maintained good visual acuity in the absence of ongoing therapy; their disease can resolve and "burn itself out". 14;19;20 Although the visual outcome in many children is favorable, approximately $19 \%$ develops unilateral legal blindness. ${ }^{14}$

One of the major questions in IU is whether it is possible to predict which patients are at greater risk of developing severe course of IU with visual loss before the sightthreatening complications actually occur. It has been reported that children with IU might have a more severe disease and worse outcome than patients with onset at older age. ${ }^{21-23}$, but these findings could not be confirmed in other studies. ${ }^{17 ; 19}$ 


\section{Patients and methods}

Medical charts of all pediatric patients with idiopathic IU examined at the department of Ophthalmology, University Medical Center, Utrecht, The Netherlands, were reviewed. The patients were collected from the data-base of our institution between 1989 and 2009. All 35 patients with the onset of their IU before the age of 16 years and a minimum follow-up of 1 year were included into this study. Diagnosis of IU and PP was made in agreement with the criteria of the SUN workgroup. ${ }^{2}$ Combination with anterior segment inflammation was allowed.

All children were evaluated by a pediatrician and/or pediatric immunologist before the idiopathic nature of IU was concluded.

Numerous data from the medical charts of the patients were recorded including demographics, date of diagnosis of IU, laterality of ocular disease, extent of diagnostic procedures and duration of follow-up were noted. Presence and date of onset of all ocular signs and complications were noted. Due to difficulties in objective measurement of cataract formation, we have used cataract surgery as a measure for cataract. Secondary glaucoma was defined as the presence of pathologic cupping of the optic disc and/or a glaucomatous visual field defect, in combination with intraocular pressure (IOP) higher than $21 \mathrm{mmHg}$ or both. ${ }^{24}$ Cupping of the optic disc was defined as pathologic when there was a C/D difference of greater than 0.2 between bellow eyes or when an increase of cupping was noted compared to the previous visit. CME was defined as the presence of macular thickening with cyst formation seen by funduscopy and/or by optical coherence tomography (OCT). Vitreous involvement was classified into 
2 categories: presence of cells in vitreous or presence of dense vitreous opacities (in addition to cells). Vitreous opacities were quantified according to the recommendations of SUN working group by slitlamp examination for the anterior vitreous and funduscopy of the posterior vitreous. ${ }^{2}$ Vasculitis was scored if vascular sheating/ leakage were observed on fundoscopy and/or angiography. Duration of uveitis was calculated from the date of diagnosis of IU. All surgical procedures and pharmacologic treatment options (with initiation and withdrawal date) were registered as well. Remission of IU was defined as absence of inflammatory activity in both anterior chamber and vitreous and no signs of snowballs and/or snowbanking for at least one year in the absence of antiinflammatory therapy. There were no children who were lost to follow-up within the first year after the discontinuation of the therapy.

In addition to examination by an ophthalmologist specialized in childhood uveitis, all children were examined by an orthoptist at initial visit and regularly evaluated during the follow-up. None of the study population had causes of amblyopia other than IU. Standard frequency of follow-up examinations was approximately once every 2-3 months.

Patients were subdivided according to age at onset of IU into a younger-onset (IU onset $\leq 7$ years of age) and older-onset group (IU onset $>7$ years of age). This approach was chosen to allow bivariate comparisons and survival analysis between the groups.

Best corrected visual acuities (BCVA's) were scored at onset of IU and during the follow-up. Snellen BCVA's were converted into the logarithm of the minimum angle of resolution scale (logMAR) for statistical analysis and converted back to Snellen BCVA's for data presentation. ${ }^{25}$ Legal blindness was defined as BCVA of the affected eye of $20 / 200$ or worse. ${ }^{26}$ In the analysis of visual outcome only the eyes with vision loss due 
to uveitis or related complications were included. Visual acuities were analyzed by eye (with an adjustment for paired eyes), further data were analyzed by patient. ${ }^{27}$

Statistical analysis of the data was performed with SPSS 15.0.1. The Pearson's Chi ${ }^{2}$ or Fisher's exact test were used for univariate analysis of categorical variables. Means were compared with Student's t-test for normally and Mann-Whitney's U-test for abnormally distributed variables. Kaplan-Meier survival analysis with a log-rank test was used to analyze survival and to compare groups. Cox proportional hazard regression was applied for multivariate analysis of variables significant in univariate analysis. BCVA's were analyzed using linear regression with GEE as adjustment for paired eyes. ${ }^{26} \mathrm{P}$-values of $\leq 0.05$ were considered statistically significant. For presentation we used means if data were distributed normally (by Kolmogorov-Smirnov test) and medians if it was not. All significances are 2-tailed and nominal.

\section{Results}

General characteristics of the study group and subgroups according to the age of IU onset are presented in Table 1. Thirty-one patients (89\%) fulfilled the criteria of $\mathrm{PP}^{2}$, four remaining patients did not show the presence of snowballs and/or snowbanking during their follow-up. In 10/35 (29\%) patients, diagnosis of IU was made during routine ophthalmologic examination without ocular complaints and the others were referred to an ophthalmologist because of ocular complaint of floaters or decreased visual acuity.

Ocular signs and complications at onset of IU (initial presentation). The ocular findings at the initial presentation for the whole group, and in the groups divided according to the 
age of onset are presented in Table 2. It is notable that moderate to dense vitreous opacities $^{2}$ were significantly more frequently present in children with onset $\leq 7$ years ( $88 \%$ vs. $42 \% ; p=0.01$ ). At the initial orthoptic examination, amblyopia due to IU was present in 4 patients $(11 \%)$ and in one of them the diagnosis of IU was made during treatment for amblyopia (Table 2).

Ocular signs and complications in the course of follow-up and mean time until their development are listed in Table 3. The most frequently observed complications were papillitis $(60 \%)$ and CME $(57 \%)$ which were bilateral in the majority of cases (Table 3$)$.

Children from the onset group $\leq 7$ years developed severe sight threatening complications such as secondary glaucoma and vitreous hemorrhage $(p=0.04 ; p=0.01$ respectively; Fig. 1 and 2) earlier and more frequently. Additionally, mean age of onset in children in whom the course of IU was complicated by cataract surgery, secondary glaucoma and vitreous hemorrhage was significantly lower compared with children without this complication (respectively, 5.9 versus $8.7 ; 5.0$ versus 8.4 and 5.6 versus 8.5 years; all $p=0.03$ ).

Development of CME in the course of follow-up was univariately associated with the presence of papillitis and snowbanking at onset (both $p<0.01$ ). In a multivariate analysis, adjusted for age of uveitis onset and gender, the presence at onset of both papillitis (adjusted hazard ratio $[\mathrm{HR}]=3.4 ; 95 \% \mathrm{Cl} 1.1-9.6$ ); $\mathrm{p}=0.02$ ) and snowbanking (adjusted $\mathrm{HR}=3.3 ; 95 \% \mathrm{Cl} 1.2-9.7 ; \mathrm{p}=0.03$ ) were independently associated with later development of CME. Other complications at onset were not predictive for future complications.

Treatment. All but one patient (97\%) in our series needed some form of antiinflammatory therapy during follow-up (Table 1). Topical steroids (86\%) and periocular 
steroid injections were used most frequently in all patients (resp. 86\% and 64\%). Systemic medication in the form of systemic corticosteroids and immunosuppressives was administered in respectively $34 \%$ and $14 \%$ of the patients. Table 1 demonstrates that patients with young onset seemed to be treated more intensively in our series. However, this difference reached the level of statistical significance only for the use of topical steroids ( $100 \%$ vs. $68 \% ; p=0.02)$.

Over time, anti-inflammatory therapy (topical and systemic) could be stopped completely in $24 / 35$ patients $(69 \%)$. Fifteen of these 24 patients $(63 \%)$ reached remission. Mean time to discontinuation of therapy was 2.0 years (range $0.1-6.9$ years). Mean age of discontinuation of therapy was 11.0 years ( \pm 3.1 SD; range $6.3-18.2$ years).

Continuation of any kind of therapy (topical, systemic or periocular) was significantly longer and more frequently needed in children with younger age of onset compared with the older onset group ( $\mathrm{p}=0.01$; Fig. 3 ).

Pars plana vitrectomy (PPV) was performed in $3(9 \%)$ children in cases of vitreo-retinal traction, all of them had onset of IU before 7 years of age.

Remission. In total 15 patients $(43 \%)$ of the whole group $(n=35)$ reached remission. The mean time before reaching the remission was 5.1 years ( $\pm 3.2 \mathrm{SD}$; range 1.1-11.8). Two of these 15 patients (13\%) who reached remission had a flare-up of uveitis after approximately 2 and 2.5 years of remission, respectively. The other $13 / 15$ patients $(87 \%)$ stayed in remission till the end of follow-up (mean duration of follow-up in remission 3.9 years; $\pm 2.9 \mathrm{SD}$; range 1.1-9.8 years). Mean age of reaching the remission was 13.8 years ( $\pm 3.1 \mathrm{SD}$; range $8.1-19.4)$.

In the group with onset of IU $\leq 7$ years remission was reached in $4 / 16$ patients $(25 \%)$ versus $11 / 19(58 \%)$ patients with older onset of IU $(p=0.050)$. 
Visual outcome. BCVA's in affected eyes according to the age of onset of IU at different points of FU are presented in Table 4. Children with onset of IU $\leq 7$ years had significantly worse BCVA's till up to 3 years of follow-up compared with the older onset group (all $p \leq 0.04 ;$ Table 4).

Unilateral legal blindness occurred in $7 / 35$ patients $(20 \%)$. Two of them $(2 / 7 ; 29 \%)$ already had one legally blind eye at the initial visit to an ophthalmologist for IU, with no improvement after treatment. Blindness was univariately associated with diagnosis made at routine ophthalmologic examination without ocular complaints $(p=0.04)$. There were no statistical differences in the frequency of blindness between younger (4/16; $25 \%)$ and older onset groups (3/19; $16 \%)$.

The causes of unilateral blindness included CME/maculopathy $(n=3)$, retinal detachment after vitrectomy due to epiretinal membranes $(n=2)$, recurrent vitreous hemorrhage $(n=1)$ and secondary glaucoma $(n=1)$. The child with recurrent vitreous hemorrhage was not followed in our clinic anymore since these events. The data about his later visual function was unavailable. In 2/7 (29\%) unilaterally blind patients, amblyopia due to IU played a role in the definitive loss of vision.

\section{Discussion}

The current study shows negative effect of young age at onset of IU on the clinical course and visual outcome up to 3 years follow-up.

To our knowledge this is the first study which shows the effect of young age of onset within a paediatric population with IU. A previous study on paediatric IU from our center 
had a different main goal and methodological approach with a slightly different patient selection and reported no differences at presentation between different age groups. ${ }^{14}$ In the current study we estimated the differences in the course of disease and visual outcome between younger and older onset of IU in childhood. It should be mentioned that in accordance with our earlier results, no differences in complications at presentation between different age groups were found.

Our study revealed that children with earlier onset of IU are at increased risk of vitreous haemorrhage, secondary glaucoma and cataract surgery. Vitreous haemorrhage in IU is usually caused by retinal neovascularisation. ${ }^{16}$ The fact that vitreous haemorrhage was more common in children compared to adults was reported previously by others. ${ }^{16}$ It is noteworthy that even within a paediatric population we could find higher prevalence of vitreous haemorrhage in children with onset $\leq 7$ years of age. In our series, vitreous haemorrhage took place only in children with onset before the age of 7 . The difference in prevalence of this complication in children with younger and older onset could be explained by a more severe form of disease with increased incidence of retinal neovascularisation or by late identification and treatment of neovascularisation in young children. Unfortunately, our data does not make it possible to investigate these theories, as in our series neovascularisation was observed only in two patients with older onset and none of them developed vitreous haemorrhage during their follow-up. This example illustrates the difficulty in identification of neovascularisation in young children as angiography and pars plana indentation are being performed mostly in older patients.

Worse visual outcome of children with younger onset of IU could be theoretically explained by higher frequency of the vision-threatening complications. Noteworthy is that children with younger onset had lower visual acuity at presentation. The speculative explanation for this difference could lie in the difficulty and delay of diagnosis of IU in 
young children, who mostly do not complain about decrease in vision. Vitreous opacities, which were more frequent in young children at presentation, could indicate more severe disease at presentation and lead to worse vision at presentation. Additional potential risk and danger in this group of young children is the development of amblyopia, which, as we show in our series, can occur in a sizable proportion of patients and contribute to their poor visual outcome.

Although almost all patients in our series needed some form of treatment during their disease course, the therapy could be completely stopped in almost $70 \%$ after the mean interval of 2 years. In accordance with earlier results from our center, we show the therapy-free remission of over 1 year in more than a third of patients. ${ }^{14}$ An interesting finding of this study is that children with younger onset of IU needed more prolonged and intensive treatment, which could be discontinued less frequently and their disease burned out significantly less often. Mean age when remission was reached was 13.8 years and no one of the patients reached remission before the age of 8 years. These facts could indirectly indicate the severity of disease in younger children. As we discussed above, children with young age at onset were at increased risk of complications despite the fact that and they received a more intensive treatment. On the one hand the given treatment might have been insufficient for their severe inflammation but on the other hand secondary glaucoma and cataract can also be associated with administration of corticosteroids. It is not possible to make a reliable distinction between a more severe inflammation and more intensive use of corticosteroids as a cause for these complications in our data set. More frequent use of topical steroids in children with young onset could be related to a more frequent involvement of the anterior chamber. However, this difference did not reach the level of statistical significance in our series at onset Presence of anterior segment inflammation later in the follow-up was not scored. 
Papillitis and CME were the most frequent complications of IU, which is in accordance to other reports. ${ }^{14 ; 18 ; 23 ; 28}$ We confirmed the clinical suspicion about the association of these two complications ${ }^{14}$ by showing that the presence of papillitis at onset is an independent prognostic factor for development of CME later. We consider this a clinically relevant finding since CME is known as a major cause of poor visual prognosis in these patients ${ }^{14 ; 20 ; 28}$ and is being used as a treatment indication. ${ }^{14 ; 28}$ Development of CME was also independently associated with the presence of snowbanking at initial presentation. The knowledge of early risk factors for CME might help in the identification and the evaluation of patients who are at risk of this sight-threatening complication.

Several limitations should be mentioned for this study. First, the retrospective study design makes it impossible to account for all possible confounders and complicates the interpretation of cause and consequence. Cataract surgery was chosen as a measurement for cataract. Although this is not a completely objective measurement, but in a retrospective study it solves problem of frequently incomplete documentation of cataract development and observations by different ophthalmologists during the followup. As the study was performed in a tertiary centre specialized in uveitis, the milder and uncomplicated cases might be lost to follow-up earlier, so the cumulative complication rates can be overestimated due to a selection bias. Relatively limited number of patients with small number of events increases the likelihood of type II error (inability to confirm significant difference when it actually exists). The chosen cut point of 7 years is arbitrary. It was chosen due to the fact that it is being generally assumed that children before this age have more chance to develop amblyopia. The choice of this cut point resulted in two statistically comparable groups. Furthermore, the higher complication rate in young children is confirmed by the analysis of age as a continuous variable in children with and without complications. 
In conclusion, our study emphasizes increased risk of a complicated and more prolonged course of disease and worse visual outcomes in children with younger onset of IU. We show that the presence of papillitis and snowbanking at onset of IU is associated with later development of CME. Our results could help a clinician to identify children with IU who carry higher risk of complications and worse visual outcome. We would recommend considering more intensive monitoring and earlier threshold for systemic treatment in those children with risk factors as early onset, disc oedema and/or snowbanking at initial presentation. 


\section{Acknowledgments/ disclosure}

"The Corresponding Author has the right to grant on behalf of all authors and does grant on behalf of all authors, an exclusive licence (or non exclusive for government employees) on a worldwide basis to the BMJ Publishing Group Ltd and its Licensees to permit this article (if accepted) to be published in BJO editions and any other BMJPGL products to exploit all subsidiary rights, as set out in our licence(http://group.bmj.com/products/journals/instructions-for-authors/licence-forms/)."

Competing interest: none to declare

Funding: The study was financially supported by following Dutch non-government scientific funds: Dr. F.P. Fisher Stichting, Stichting Nederlands Oogheelkundig Onderzoek and ODAS-Stichting.

Financial disclosures: The authors declare no financial conflict of interest. Funding entities had no role in the conduction or presentation of this study.

Contribution of authors: design of the study (V.K.A., J.H.B., A.R.), data collection (V.K.A., H.A.T.C), data management and analysis (V.K.A.), data interpretation (V.K.A., P.D., J.H.B., A.R.), preparation of initial manuscript (V.K.A.), critical revision of initial manuscript (J.H.B., A.R.).

Other acknowledgments: The IRB at Utrecht University has declared that this type of research does not require IRB approval. 


\section{Reference List}

1. Nagpal A, Leigh JF, Acharya NR. Epidemiology of uveitis in children. Int Ophthalmol Clin 2008;48:1-7.

2. Jabs DA, Nussenblatt RB, Rosenbaum JT. Standardization of uveitis nomenclature for reporting clinical data. Results of the First International Workshop. Am J Ophthalmol 2005;140:509-16.

3. Romero R, Peralta J, Sendagorta E, Abelairas J. Pars planitis in children: epidemiologic, clinical, and therapeutic characteristics. J Pediatr Ophthalmol Strabismus 2007;44:288-93.

4. Alaez C, Arellanes L, Vazquez A, et al. Classic Pars Planitis: strong correlation of class II genes with gender and some clinical features in Mexican Mestizos. Hum Immunol 2003;64:965-72.

5. Raja SC, Jabs DA, Dunn JP, et al. Pars planitis: clinical features and class II HLA associations. Ophthalmology 1999;106:594-9.

6. Cuccia BM, Martinetti M, De PF, et al. Genetic heterogeneity in uveitis. Dis Markers 1986;4:243-6.

7. Martin T, Weber M, Schmitt C, et al. Association of intermediate uveitis with HLAA28: definition of a new systemic syndrome? Graefes Arch Clin Exp Ophthalmol 1995;233:269-74.

8. Tang WM, Pulido JS, Eckels DD, et al. The association of HLA-DR15 and intermediate uveitis. Am J Ophthalmol 1997;123:70-5.

9. Culbertson WW, Giles CL, West C, Stafford T. Familial pars planitis. Retina 1983;3:179-81.

10. Augsburger JJ, Annesley WH, Jr., Sergott RC, et al. Familial pars planitis. Ann Ophthalmol 1981;13:553-7.

11. Duinkerke-Eerola KU, Pinckers A, Cruysberg JR. Pars planitis in father and son. Ophthalmic Paediatr Genet 1990;11:305-8.

12. Tejada P, Sanz A, Criado D. Pars planitis in a family. Int Ophthalmol 1994;18:1113.

13. Lee AG. Familial pars planitis. Ophthalmic Genet 1995;16:17-9.

14. de Boer J, Berendschot TT, van der DP, Rothova A. Long-term follow-up of intermediate uveitis in children. Am J Ophthalmol 2006;141:616-21.

15. Jain R, Ferrante P, Reddy GT, Lightman S. Clinical features and visual outcome of intermediate uveitis in children. Clin Experiment Ophthalmol 2005;33:22-5. 
16. Lauer AK, Smith JR, Robertson JE, Rosenbaum JT. Vitreous hemorrhage is a common complication of pediatric pars planitis. Ophthalmology 2002;109:95-8.

17. Malinowski SM, Pulido JS, Folk JC. Long-term visual outcome and complications associated with pars planitis. Ophthalmology 1993;100:818-24.

18. Arellanes-Garcia L, Navarro-Lopez L, Recillas-Gispert C. Pars planitis in the Mexican Mestizo population: ocular findings, treatment, and visual outcome. Ocul Immunol Inflamm 2003;11:53-60.

19. Vidovic-Valentincic N, Kraut A, Hawlina M, et al. Intermediate uveitis: long-term course and visual outcome. Br J Ophthalmol 2009;93:477-80.

20. Donaldson MJ, Pulido JS, Herman DC, et al. Pars planitis: a 20-year study of incidence, clinical features, and outcomes. Am J Ophthalmol 2007;144:812-7.

21. Aaberg TM. The enigma of pars planitis. Am J Ophthalmol 1987;103:828-30.

22. Guest S, Funkhouser E, Lightman S. Pars planitis: a comparison of childhood onset and adult onset disease. Clin Experiment Ophthalmol 2001;29:81-4.

23. Hogan MJ, Kimura SJ, O'Connor GR. Peripheral retinitis and chronic cyclitis in children. Trans Ophthalmol Soc U K 1965;85:39-52.

24. Sijssens KM, Rothova A, Berendschot TT, de Boer JH. Ocular hypertension and secondary glaucoma in children with uveitis. Ophthalmology 2006;113:853-9.

25. Holladay JT. Visual acuity measurements. J Cataract Refract Surg 2004;30:28790.

26. Tielsch JM, Sommer A, Witt $\mathrm{K}$, et al. Blindness and visual impairment in an American urban population. The Baltimore Eye Survey. Arch Ophthalmol 1990;108:286-90.

27. Katz J, Zeger S, Liang KY. Appropriate statistical methods to account for similarities in binary outcomes between fellow eyes. Invest Ophthalmol Vis Sci 1994;35:2461-5.

28. Arellanes-Garcia L, Navarro-Lopez P, Concha-Del Rio LE, Unzueta-Medina JA. Idiopathic intermediate uveitis in childhood. Int Ophthalmol Clin 2008;48:61-74 


\section{Figure captures}

Figure 1. Survival plot for secondary glaucoma in patients with onset of intermediate uveitis (IU) before and after 7 years of age.

Figure 2. Survival plot for vitreous hemorrhage in patients with onset of intermediate uveitis (IU) before and after 7 years of age.

Figure 3. Survival plot for discontinuation of the therapy in patients with onset of intermediate uveitis (IU) before and after the age of 7 years. 


\section{Tables}

Table 1. General characteristics and therapy of patients with idiopathic intermediate uveitis according to age of uveitis onset.

\begin{tabular}{|c|c|c|c|c|}
\hline \multirow{2}{*}{ Characteristics } & \multirow{2}{*}{$\begin{array}{l}\text { Total } \\
\mathrm{N}=35\end{array}$} & \multicolumn{2}{|c|}{ Age of uveitis onset } & \multirow{2}{*}{ p-value } \\
\hline & & $\begin{array}{c}0-7 \text { years } \\
N=16(\%)\end{array}$ & $\begin{array}{l}7-16 \text { years } \\
\mathrm{N}=19(\%)\end{array}$ & \\
\hline Female gender (N;\%) & $10(29)$ & $4(25)$ & $6(32)$ & 0.72 \\
\hline Bilateral disease (N;\%) & $33(94)$ & $16(100)$ & $17(90)$ & 0.49 \\
\hline Follow-up years (median; range) & $4,0(1,3-16,9)$ & $4,3(2,4-16,7)$ & $4,0(1,3-14,1)$ & 0.22 \\
\hline Topical steroids (N;\%) & $30(86)$ & $16(100)$ & $14(74)$ & 0.05 \\
\hline Periocular steroid injections (N;\%) & $24(69)$ & $12(75)$ & $12(63)$ & 0.45 \\
\hline Systemic corticosteroids (N;\%) & $12(34)$ & $7(44)$ & $5(26)$ & 0.28 \\
\hline Immunomodulatory therapy $(\mathrm{N} ; \%)^{\mathrm{a}}$ & $5(14)$ & $4(25)$ & $1(5)$ & 0.16 \\
\hline
\end{tabular}


Table 2. Frequency of ocular signs and complications at initial presentation in children with intermediate uveitis (IU) according to the age of onset.

\begin{tabular}{|c|c|c|c|c|}
\hline \multirow[b]{2}{*}{ Complications and ocular findings at onset of IU } & \multirow{2}{*}{$\begin{array}{c}\text { Total } N=35 \\
(\%)\end{array}$} & \multicolumn{2}{|c|}{ Age of uveitis onset } & \multirow{2}{*}{$p$-value ${ }^{a}$} \\
\hline & & $\begin{array}{l}0-7 \text { years } \\
N=16(\%)\end{array}$ & $\begin{array}{l}7-16 \text { years } \\
N=19(\%)\end{array}$ & \\
\hline Vitreous opacities (moderate to dense) ${ }^{\mathrm{b}}(\mathrm{N} ; \%)$ & $22(63)$ & $14(88)$ & $8(42)$ & 0.01 \\
\hline Anterior chamber inflammation $(\mathrm{N} ; \%)$ & $11(31)$ & $6(38)$ & $5(26)$ & 0.48 \\
\hline Cystoid Macular Edema (N;\%) & $10(29)$ & $4(25)$ & $6(32)$ & 0.72 \\
\hline Papillitis (N;\%) & $9(26)$ & $5(31)$ & $4(21)$ & 0.70 \\
\hline Snowballs (N;\%) & $6(17)$ & $2(13)$ & $4(21)$ & 0.67 \\
\hline Snowbanking (N;\%) & $6(17)$ & $2(13)$ & $4(21)$ & 0.67 \\
\hline Amblyopia (N;\%) & $4(11)$ & $4(25)$ & ND & $\mathrm{NC}$ \\
\hline Posterior synechiae (N;\%) & $2(6)$ & $2(13)$ & ND & 0.20 \\
\hline Vasculitis (N;\%) & $2(6)$ & NA & $2(11)$ & 0.49 \\
\hline Epiretinal membranes (N;\%) & $2(6)$ & $1(6)$ & $1(5)$ & 1.00 \\
\hline Bandkeratopathy (N;\%) & $1(3)$ & $1(6)$ & ND & 0.46 \\
\hline Cataract $(\mathrm{N} ; \%)^{\mathrm{C}}$ & $1(3)$ & $1(6)$ & ND & 0.46 \\
\hline Vitreous haemorrhage (N;\%) & $1(3)$ & $1(6)$ & ND & 0.46 \\
\hline
\end{tabular}

$\mathrm{ND}=$ not detected

$\mathrm{NC}=$ not comparable

${ }^{a}$ p-values are computed with Fisher exact test

${ }^{b}$ According to the SUN classification ${ }^{2}$ 
${ }^{c}$ In one child diagnosis of IU was made directly after cataract extraction. 
Table 3. Frequency and time of development of complications, during the follow-up of children with intermediate uveitis (IU) according to the age of onset.

\begin{tabular}{|c|c|c|c|c|c|}
\hline \multirow{2}{*}{$\begin{array}{l}\text { Complications and ocular findings } \\
\text { during the course of IU }\end{array}$} & \multirow{2}{*}{$\begin{array}{c}\text { Total }(\mathrm{N} ; \%) \\
\quad N=35\end{array}$} & \multirow{2}{*}{$\begin{array}{l}\text { Bilateral } \\
\qquad(\%)\end{array}$} & \multicolumn{2}{|c|}{ Age of uveitis onset } & \multirow{2}{*}{$\begin{array}{l}\text { Mean time to } \\
\text { development } \\
\text { (years } \pm S D \text { ) }\end{array}$} \\
\hline & & & $0-7$ years $(\mathrm{N} ; \%)$ & $7-16$ years $(\mathrm{N} ; \%)$ & \\
\hline Papillitis (N;\%) & $21(60)$ & 90 & $N=16$ & $N=19$ & $0.7( \pm 1.1)$ \\
\hline CME (N;\%) & $20(57)$ & 70 & $10(63)$ & $10(53)$ & $0.6( \pm 1.3)$ \\
\hline Vasculitis (N;\%) & $16(46)$ & 63 & $8(50)$ & $8(44)$ & $1.8( \pm 1.8)$ \\
\hline Cataract surgery (N;\%) & $9(26)$ & 22 & $7(44)$ & $2(11)$ & $2.6( \pm 2.1)$ \\
\hline Secondary glaucoma $(\mathrm{N} ; \%)$ & $4(11)$ & NA & $4(25)$ & ND & $2.9( \pm 2.1)$ \\
\hline Vitreous haemorrhage $(\mathrm{N} ; \%)$ & $6(17)$ & 17 & $6(38)$ & ND & $3.2( \pm 2.9)$ \\
\hline Bandkeratopathy (N;\%) & $6(17)$ & 17 & $5(31)$ & $1(5)$ & $3.2( \pm 2.4)$ \\
\hline Amblyopia (N;\%) & $6(17)$ & NA & $6(38)$ & ND & $0.5( \pm 1.2)$ \\
\hline Posterior synechiae (N;\%) & $5(14)$ & 20 & $3(19)$ & $2(11)$ & $0.7( \pm 1.1)$ \\
\hline Epiretinal membranes $(\mathrm{N} ; \%)$ & $5(14)$ & 40 & $4(25)$ & $1(5)$ & $1.9( \pm 2.1)$ \\
\hline Retinal detachment $(\mathrm{N} ; \%)$ & $3(9)$ & NA & $2(13)$ & $1(5)$ & $1.2( \pm 1.4)$ \\
\hline Retinal neovascularisation (N;\%) & $2(6)$ & NA & NA & $2(11)$ & $0.6( \pm 0.6)$ \\
\hline
\end{tabular}

$\mathrm{ND}=$ not detected 
Table 4. Best corrected visual acuities (BCVA's) according to the age of onset in eyes affected with intermediate uveitis (IU).

\begin{tabular}{|c|c|c|c|c|}
\hline \multirow{2}{*}{ Visual acuity } & \multirow{2}{*}{ Total } & \multicolumn{2}{|c|}{ Mean of $B C V A^{a}$} & \multirow{2}{*}{$p$-value ${ }^{b}$} \\
\hline & & $0-7$ years & $7-16$ years & \\
\hline \multicolumn{5}{|l|}{ At onset } \\
\hline Number of eyes in analysis ${ }^{c}$ & 63 & 29 & 34 & \\
\hline - Median BCVA ${ }^{\mathrm{a}}$ & 0.4 & 0.3 & 0.6 & 0.04 \\
\hline \multicolumn{5}{|l|}{1 yr of follow-up } \\
\hline Number of eyes in analysis & 61 & 26 & 35 & \\
\hline - Median BCVA ${ }^{\mathrm{a}}$ & 0.8 & 0.4 & 0.9 & 0.03 \\
\hline \multicolumn{5}{|l|}{3 yrs of follow-up } \\
\hline Number of eyes in analysis & 49 & 29 & 20 & \\
\hline - Median BCVA ${ }^{a}$ & 0.7 & 0.6 & 0.9 & 0.01 \\
\hline \multicolumn{5}{|l|}{5 yrs of follow-up } \\
\hline Number of eyes in analysis & 27 & 16 & 11 & \\
\hline - Median BCVA ${ }^{a}$ & 0.8 & 0.6 & 0.8 & 0.09 \\
\hline
\end{tabular}

${ }^{a}$ For the analysis of BCVA's all decimal Snellen BCVA's were f transformed to their logMAR equivalents and afterwards back to decimal VA's, which are presented.

${ }^{b} p$-values computed by linear regession with generalized estimating equations (GEE) as adjustment for paired eyes

${ }^{\mathrm{c}}$ excluding eyes with missing data about vision at initial presentation. 
Survival function for development of secondary glaucoma

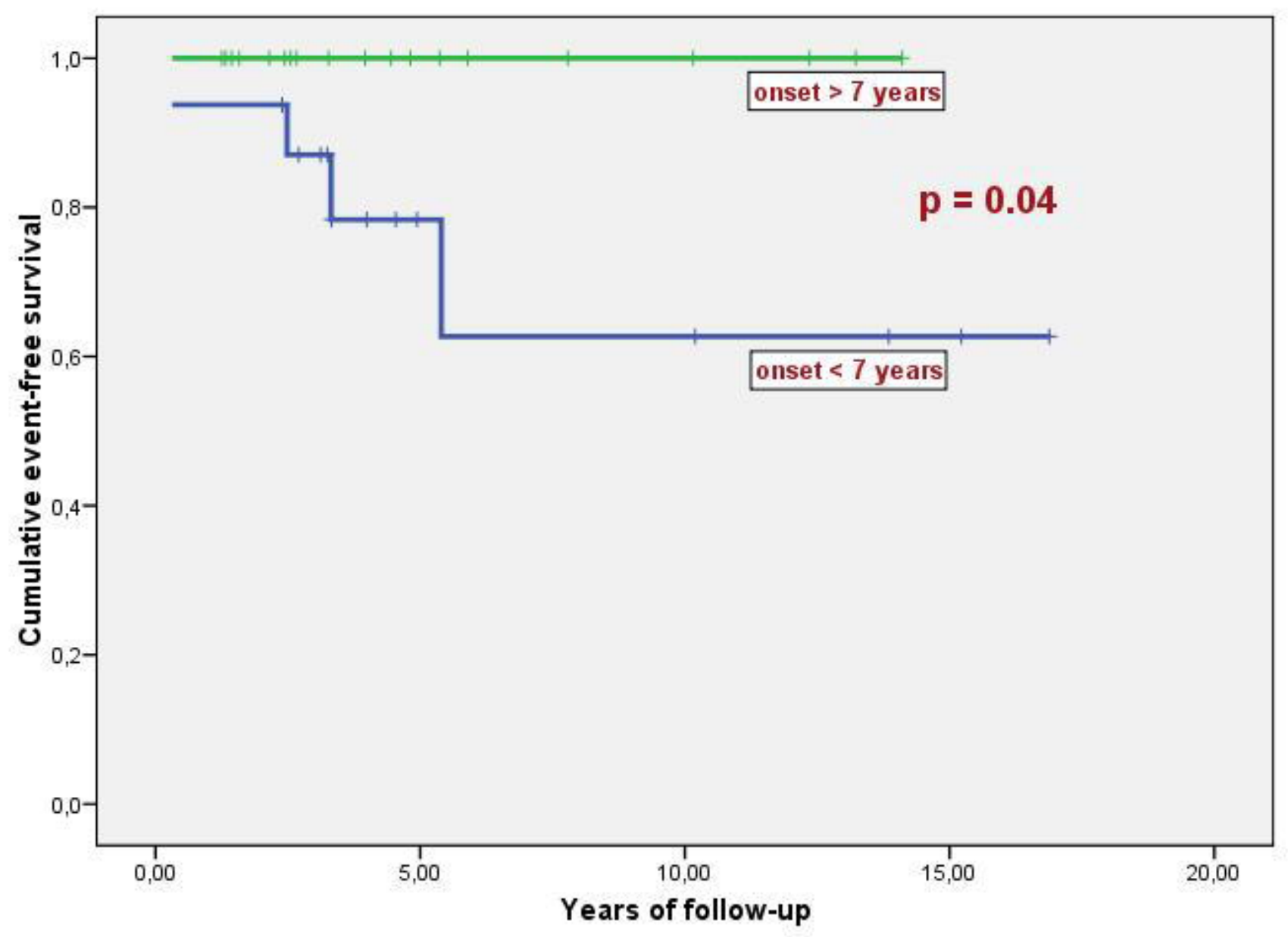


Survival function for development of vitreous haemorrhage

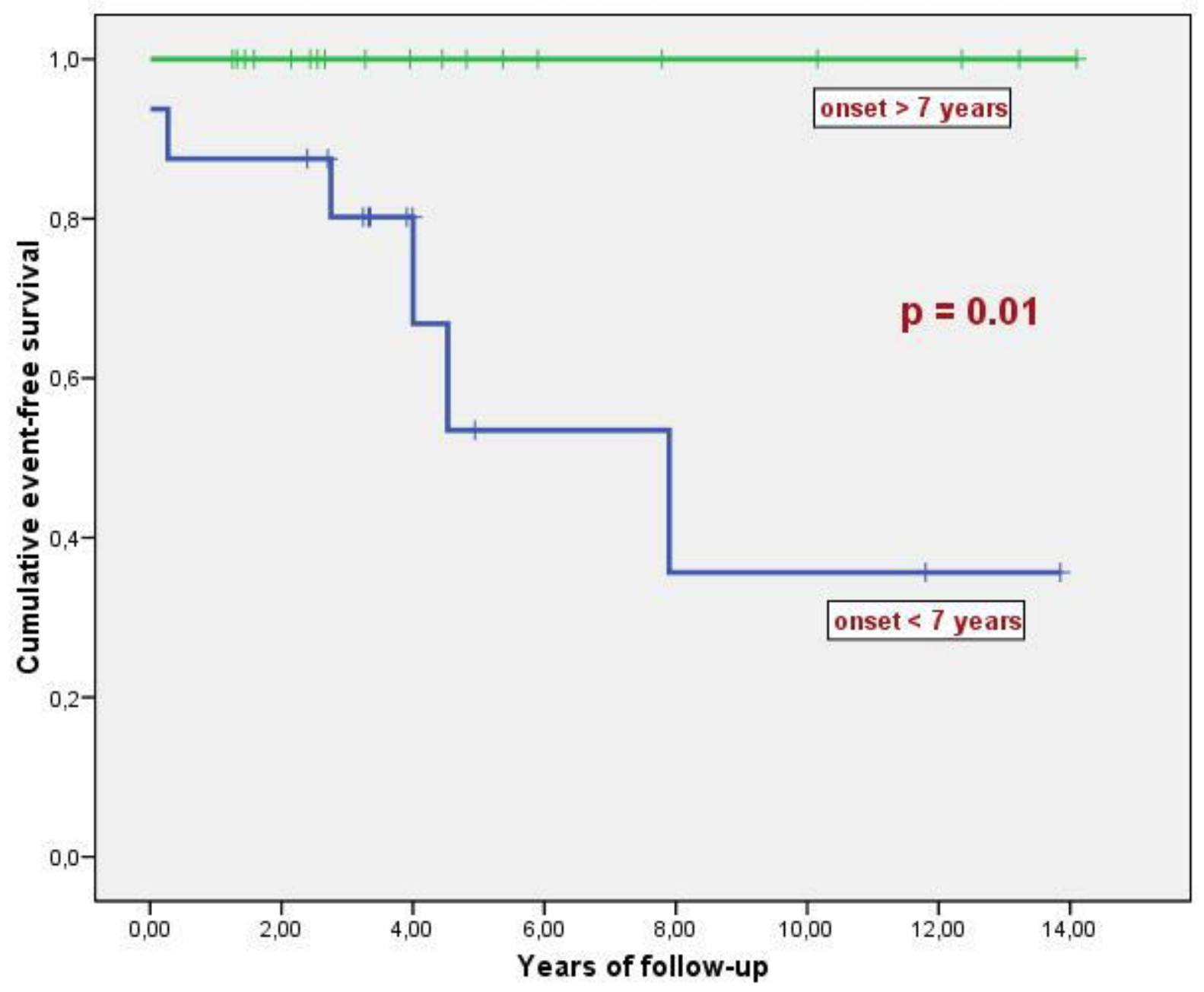




\section{Survival function for discontinuation of therapy}

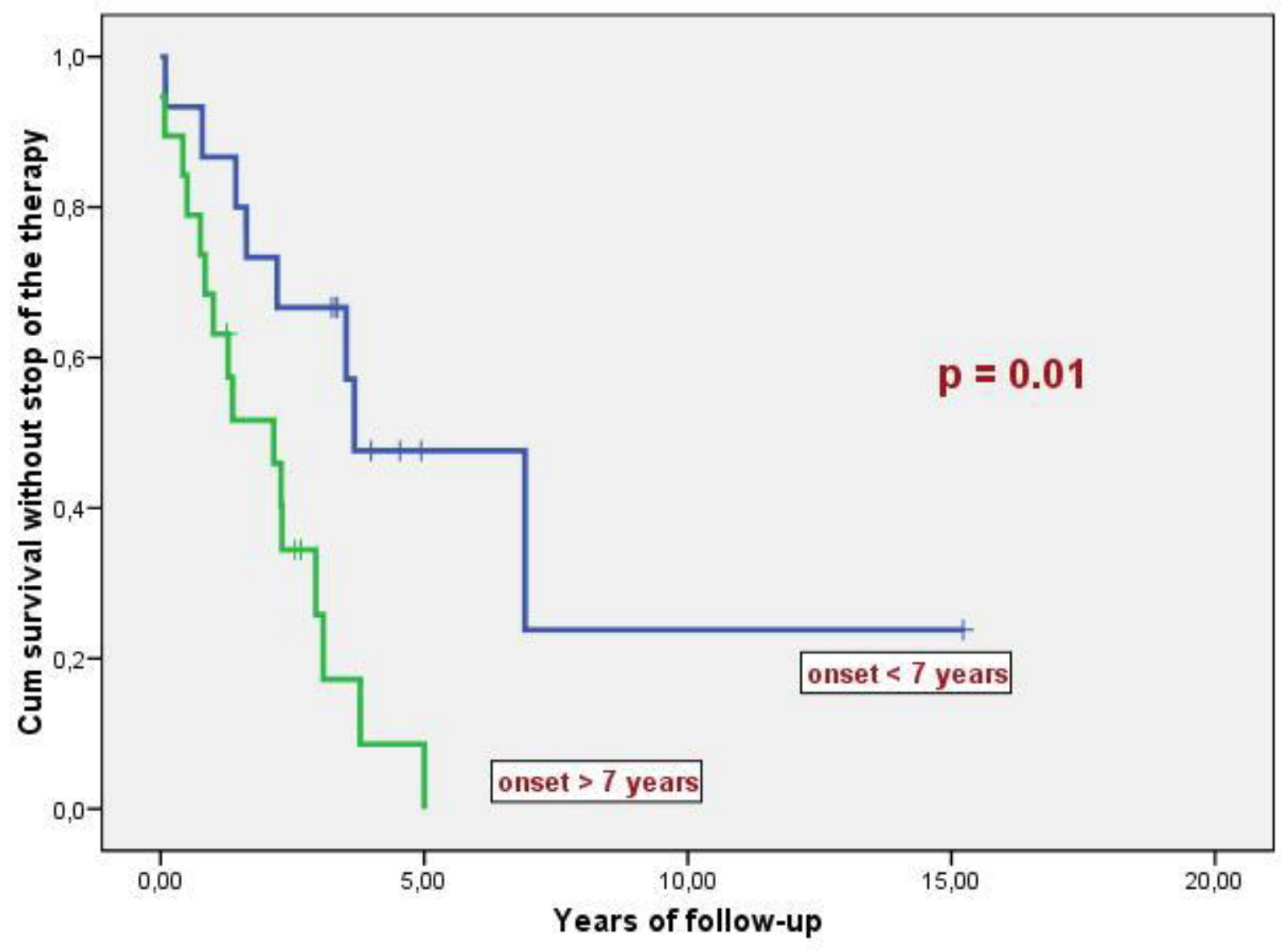

